Check for updates

Cite this as: $B M J 2021 ; 372: n 720$ http://dx.doi.org/10.1136/bmj.n720 Published: 19 March 2021

\section{How doctors can help end food insecurity}

This feature (BMJ 2021;372:n53, doi:, 13 January 2021) wrongly attributed the development of the "hunger vital sign" food insecurity tool to the American Academy of Pediatrics and the US based Food Research and Action Center. This collaboration developed a toolkit that was based on a tool developed by Children's HealthWatch, with the University of Maryland School of Medicine. 